\title{
Architecture Development of Wrist Range-of-Motion (ROM) System to Assess and Monitor Wrist Postural Behaviours at Workplace: An Exploratory Study
}

\author{
Radin Zaid Radin Umar*, Nadiah Ahmad, Isa Halim and Nazreen Abdullasim \\ Centre of Smart System and Innovative design, Fakulti Kajuruteraan Pembuatan, University Teknikal alaysia Melaka, Hang Tuah Jaya, \\ 76100, Melaka, Malaysia
}

Received 3 December 2018; Accepted 30 November 2019

\begin{abstract}
Poor wrist postures due to work requirements is one of the established risk factors contributing to the development of workrelated musculoskeletal disorders. This study systematically investigates the underlying hypothesis that identification and monitoring of poor wrist postures at work should be in the function of normalized wrist range-of-motion (ROM) instead of the traditional measurement of absolute wrist angle. This three-stage study looks into 1) existing issues related to current workplace wrist postural assessment methods, 2) development of a new architecture to assess and monitor wrist posture at work, and 3) qualitative review with ergonomics practitioners on the architecture. The first stage utilizes literature review and interview with ergonomics practitioners. Generative collaboration method was used to generate the architecture for the second stage. The third stage employs semi-structured interview with ergonomics practitioners. Several issues were identified in current wrist postural assessment methods. A conceptual architecture of the Wrist ROM System to assess and monitor wrist postural behaviors at workplace is proposed in this manuscript. The architecture was generally well received by the practitioners. The architecture provides the groundwork in the development of a technological system designed as a tool to analyze workplace wrist postural behaviors.
\end{abstract}

Keywords: ergonomics; range of motion; assessment; wrist posture;

\section{Introduction}

Several ergonomics risk factors are known to be associated with the occupational sprain and strain as well as work musculoskeletal disorders (WMSDs). Among these risk factors are poor working postures, high force exertion, repetitive joint movements, and their combinations [1]. Among others, these risk factors may also exist due to the substandard workplace and tool design, as well as employees' working behaviors and habits. The US Bureau of Labor reported sprain and strain as the leading nature of occupational injury and illness, which accounted for $37 \%$ of total cases requiring days away from work in 2014 [2]. The emerging trend of occupational injuries due to sprain and strain, especially related to the upper extremities would negatively affect workers and industries such as causing long absences from work [3], and loss of productivity or wages [4].

National Institute of Occupational Safety and Health (NIOSH) reported that adoption of non-neutral wrist posture can increase risks to musculoskeletal disorders such as Carpal Tunnel Syndrome (CTS) or tendinitis [5]. Frequent and extreme deviation from neutral wrist posture have shown association to alter carpal tunnel pressure, affecting median nerve compression, and ultimately leading to higher risk of chronic WMSDs development [6 - 10]. Wrist injuries have been reported to contribute to a considerable economic burden associated with both high health-care costs and productivity costs [11]. Costs associated with CTS related

*E-mail address: radinzaid@utem.edu.my

ISSN: 1791-2377 @ 2019 School of Science, IHU. All rights reserved.

doi:10.25103/iestr.126.10 surgeries were estimated to be USD 2 billion each year, with approximately 400,000 surgeries reported to be performed [12]. Thus, a mechanism to detect and classify the poor wrist posture at work is needed. However, review of the literature shows that the identification and quantification of wrist postures at work is challenging [13, 14]. Multiple workplace factors such as high work pace, limited space, repetitive task [15], and restricted vision resulted in the difficulties to observe and quantify the wrist posture behaviors.

This manuscript is proposing a conceptual idea that the identification and monitoring of poor wrist postures should be quantitative and real time. In addition, the identification and monitoring is proposed to be in the function of normalized wrist range of motion (ROM) to complement the traditional measurement of absolute wrist angle or the subjective assessment systems (self-report and observation). It is envisioned that a modular real-time system of wrist ROM can provide industrial practitioners a tool to identify and monitor wrist posture in workplace. This proposed system may assist designers, engineers, and management in identifying, analyzing and making changes to workstation and tool design to improve wrist postural behaviors.

\section{Methods}

This study consisted of three stages (Figure 1), in which each stage utilizes different research methodologies. Stage 1 is a problem investigation stage, where existing issues related to current workplace wrist postural assessment were investigated. This study was initiated after interviews with two experienced ergonomics consultants providing 
ergonomics services to industries. These two practitioners have a cumulative 30 years of experience conducting ergonomics assessment in different industrial settings. In addition, available literature on the topic of wrist postural assessment were also reviewed through online databases.

In Stage 2, an initial architecture of the newly proposed wrist posture assessment and behavioral system was developed. Cognitive mind map activities through generative collaborative approach, as described by Sanders \& Stappers [16] were utilized to generate a conceptual framework of the new system. Reiterations of the conceptual frameworks lead to the development of an initial architecture for the new system to assess and monitor wrist postural behaviors at workplace.

Stage 3 is to review the proposed architecture among practitioners and academicians specializing in the area of Human Factors \& Ergonomics. Semi-structured interview sessions were conducted among 3 experts to get their feedbacks on the proposed architecture. The participants in this $3^{\text {rd }}$ stage have a cumulative experience of 55 years in the field of Human Factors \& Ergonomics. The interview sessions were audio-recorded and qualitatively analyzed for descriptive patterns. Hybrid coding scheme of 'descriptive' and 'in-vivo' coding, as described by Saldaña [17] were adopted in the qualitative thematic analysis.

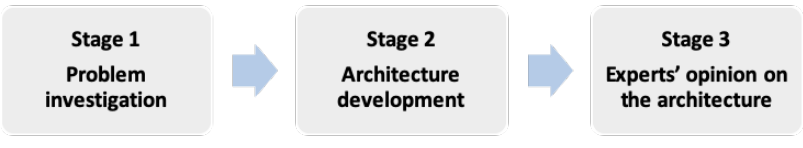

Fig. 1 The different stages in this study.

\section{Results}

\subsection{Problem investigation}

The two ergonomic consultants interviewed in this study reported an increasing cases of wrist issues among their clients. According to them, the assessment and monitoring of wrist at work is challenging with currently available postural assessment tools. Further follow up discussions identified those issues to be related to challenges in the measurement and quantification of the wrist posture behaviors. Rapid dynamic wrist movement is difficult to capture and track over a period of time.

Assessment of postures in general has been a topic of interest by researchers for few decades. Different postural assessment tools have been used by ergonomists and industrial practitioners around the world including USA, Mexico, Italy, Iran, China, India and Malaysia [18 - 25]. Reviews of literature found several postural assessment tools that are published and applied in the industries to assess workstations at occupational settings. Rapid Upper Limb Assessment (RULA) for example, is a rapid assessment tool developed to screen loads on musculoskeletal system due to posture, muscle function, and the forces upon those postures [26]. In RULA, the postural angles of different joints are observed, whereby extreme joint angle is associated with higher musculoskeletal load on the body. Rapid Entire Body Assessment (REBA) which was developed based upon RULA, also uses similar principles of focusing on postural angle as an assessment system to quantify the severity of posture [27]. The Concise Exposure Index (OCRA), which provides the assessor with an index measure uses a simpler cut off point of 45 degree wrist angle deviation in combination with frequency of exposure when assessing the wrist [28]. Quick Exposure Checklist (QEC) is another observational assessment tool that uses an assessment worksheet [29]. The worksheet accounts both the observer's and worker's rating in its assessment. The wrist assessment in QEC is divided into two components: 1) posture (either straight or bent position in worst case scenario) and, 2) frequency of posture. It should be noted that QEC does not involve an observation of any specific cutoff wrist angles, unlike RULA, REBA, and OCRA. However, similar to RULA, REBA, and OCRA, QEC's assessment is not limited only to wrist region, but also to multiple body parts such as shoulder, arm, neck, and back.

In addition to postural assessment tools that focuses on multiple body parts, there are also other tools that specifically focuses on assessing wrist posture. Strain Index considers multiple parameters in its assessment which includes wrist postures, frequency of posture assumption, duration of task, and intensity of exertion [13]. On the other hand, American Conference of Governmental Industrial Hygienists (ACGIH) developed an assessment tool called ACGIH Hand Activity Level (ACGIH-HAL) which looked at only into two parameters: hand activity level and normalized peak force [30]. The hand activity level includes the combination of the wrist posture and its frequency while peak force looks into the magnitude of hand exertion.

A closer inspection on these assessment tools reveal several research questions related to postural assessment on the wrist region. The first question on these available tools is on their specificity to assess wrist postures. RULA, REBA and OCRA considers wrist deviation from neutral posture to be one of the parameters in their assessment. However, the weight of wrist assessment in these tools is limited as the wrist score only represents small components in the overall assessment systems. Hence, the tools may not effectively quantify issues that are specific and localized to the postural behavior of the wrist.

It should be noted that few assessment tools that focus specifically on wrist motions, such as Strain Index and ACGIH-HAL already exist. Even though both Strain Index and ACGIH-HAL are specific to wrist, these tools used subjective ratings on the wrist postures to determine the assessment score. In Strain Index, the wrist posture is categorized into five subjective levels that ranges from "perfectly neutral" to "near extreme". Similarly, the measure of activity level on the wrist in ACGIH-HAL is also based on a subjective scale that ranges from $0-10$. The scale can either be determined through self-report or observation from an experienced assessor. RULA, REBA, and OCRA also use indirect measure to determine wrist angle in their respective assessment process. As such, the second question is related to the sensitivity of the tools.

Currently, there are limited instruments used to objectively assess the postural behavior at work specifically on the wrist. Estimation of wrist angle through observation, or through usage of goniometer is some of the options to capture the wrist angle. However, the dynamic nature of occupational task makes it challenging to quantify wrist posture using goniometer. Although goniometer can provide valid and reliable measurement of wrist ROM, the measurement using goniometer is usually only performed on static wrist postures [31]. Thus, the data obtained may be estimation instead of an accurate objective measure of wrist postural behaviors. The concern with subjective measure is its dependence on the experiences of assessors, as well as validity of assessment from self-report method.

Another concern related to the sensitivity of assessment is that the tools generally provide only a snapshot or an 
Radin Zaid Radin Umar, Nadiah Ahmad, Isa Halim and Nazreen Abdullasim/

Journal of Engineering Science and Technology Review 12 (6) (2019) 80 - 86

overview assessment of the posture. The capability and limitation of current instrumentations to capture rapid and real-time data may affect the quality of the data. Capturing objective, real time data may provide better data resolution for assessment, and allows an opportunity for a time-based monitoring process. It should be noted that the use of objective and real-time data when assessing specific body parts is not new. Lumbar Motion Monitor (LMM), for example, uses an electronic instruments and sensors to capture postural behaviors of spine, which includes the spine's displacement, velocity, and acceleration [32]. With the advent of new technologies such as wearable sensors, camera tracking devices and electrogoniometers, there have been few relevant studies conducted to capture real time, dynamic postural data [31, 33-36]. Thus, further exploration utilizing these technologies to have more accurate and higher resolution postural data is warranted.

Another point of discussion with current assessment tools, such as RULA, REBA or OCRA is that these tools capture absolute angle to assess posture. However, there is little consensus on the appropriate range of absolute wrist angle for occupational tasks [7]. Measurement of absolute wrist angle may not take into account existing individual factors that can influence the results of assessment. For example, a task that requires 40-degree flexion of wrist posture might not be an issue to a healthy employee, but it may be challenging to an employee who already had an onset of WMSD symptoms. Thus, it is postulated that assessment of postures should be in the function of ROM instead of an absolute angle, to account for individual differences in postural capabilities and limitations. An assessment that considers measure in the form of ROM might provide a more personalized assessment compared to absolute joint angles.

In addition to using ROM as a measure of assessment, it is also proposed that the assessment is normalized to the personal wrist active range of motion for the individual to be assessed. It is known that ROM of individuals are different from one another. Some can perform full motions, but some may have restriction in motions, due to genetics, onset of WMSDs or other factors. Thus, normalization of ROM to the individual's initial maximum voluntary ROM may account for individuals' differences. Assessment that is normalized to the maximum human capacity is not something new. Studies on electromyography (EMG) have shown the need to normalized data to the maximum voluntary capacity of the assessed individual. Using the same concept, it is envisioned that an assessment and monitoring system that normalizes the dynamic workplace wrist angle data against the maximum voluntary wrist ROM (as a benchmark of individual's capacity) may be a more sensitive assessment method.

All in all, review on existing literature of wrist postural assessment system found few gaps that warrant attention. The gaps include specificity (tool that focuses on wrist vs. other limbs) and sensitivity (subjective vs. objective measure, snapshot vs. real time data) as summarized in Table 1. A new assessment tool that specifically focuses on wrist postural behavior, and provides objective as well as real-time postural data is envisioned to provide improvement in terms of sensitivity and specificity of the assessment. In addition, using normalized ROM patterns as a method of capturing postural behavior instead of the traditional absolute angle may account for individual differences in postural capabilities and limitations.

Table 1. Comparison among existing postural assessment tools

\begin{tabular}{|c|c|c|}
\hline $\begin{array}{c}\text { Ergonomics } \\
\text { assessment tool }\end{array}$ & $\begin{array}{c}\text { Body parts } \\
\text { assessed }\end{array}$ & $\begin{array}{c}\text { Assessment data } \\
\text { type }\end{array}$ \\
\hline Strain Index [13] & $\begin{array}{l}\text { Wrists } \\
\text { region }\end{array}$ & $\begin{array}{l}\text { Qualitative } \\
\text { assessment and not } \\
\text { real time }\end{array}$ \\
\hline American & Wrists & Qualitative \\
\hline $\begin{array}{l}\text { Conference of } \\
\text { Governmental }\end{array}$ & region & $\begin{array}{l}\text { assessment and not } \\
\text { real time }\end{array}$ \\
\hline Industrial & & \\
\hline Hygienists, Hand & & \\
\hline $\begin{array}{l}\text { Activity level } \\
\text { (ACGIH-HAL) }\end{array}$ & & \\
\hline [30] & & \\
\hline RULA [26] & $\begin{array}{l}\text { Multiple } \\
\text { body parts. }\end{array}$ & $\begin{array}{l}\text { Semi quantitative } \\
\text { assessment and not } \\
\text { real time }\end{array}$ \\
\hline OCRA [28] & $\begin{array}{l}\text { Wrists } \\
\text { region }\end{array}$ & $\begin{array}{l}\text { Qualitative } \\
\text { assessment and not } \\
\text { real time }\end{array}$ \\
\hline REBA [27] & $\begin{array}{l}\text { Multiple } \\
\text { body parts. }\end{array}$ & $\begin{array}{l}\text { Semi quantitative } \\
\text { assessment and not } \\
\text { real time }\end{array}$ \\
\hline QEC [29] & $\begin{array}{l}\text { Multiple } \\
\text { body parts. }\end{array}$ & $\begin{array}{l}\text { Qualitative } \\
\text { assessment and not } \\
\text { real time }\end{array}$ \\
\hline $\begin{array}{l}\text { Real time } \\
\text { ergonomics } \\
\text { feedback system } \\
{[37]}\end{array}$ & $\begin{array}{l}\text { Multiple } \\
\text { body parts. }\end{array}$ & $\begin{array}{l}\text { Quantitative } \\
\text { assessment and real } \\
\text { time }\end{array}$ \\
\hline $\begin{array}{l}\text { Ergonomics } \\
\text { assessment } \\
\text { system proposed } \\
\text { by this study }\end{array}$ & $\begin{array}{l}\text { Wrists } \\
\text { region }\end{array}$ & $\begin{array}{l}\text { Quantitative } \\
\text { assessment and real } \\
\text { time }\end{array}$ \\
\hline
\end{tabular}

3.2 Architecture development of wrist postural behavior assessment and monitoring system at workplace

The system architecture was developed from conceptual ideas discussed with industrial practitioners and research team members. One of the components in this system is that the wrist postural behavior at workplace should be assessed and monitored using ROM instead of absolute angles. Another component is that the ROM data for individual assessment should be normalized to the maximum voluntary ROM, similar to ergonomics assessment using EMG. It is hypothesized that a real-time normalized wrist ROM data would provide a data that has a higher sensitivity and specificity for the purpose of wrist postural behavior assessment and monitoring at workplace. The architecture of the proposed wrist ROM assessment and monitoring system is summarized in Figure 2 below. 


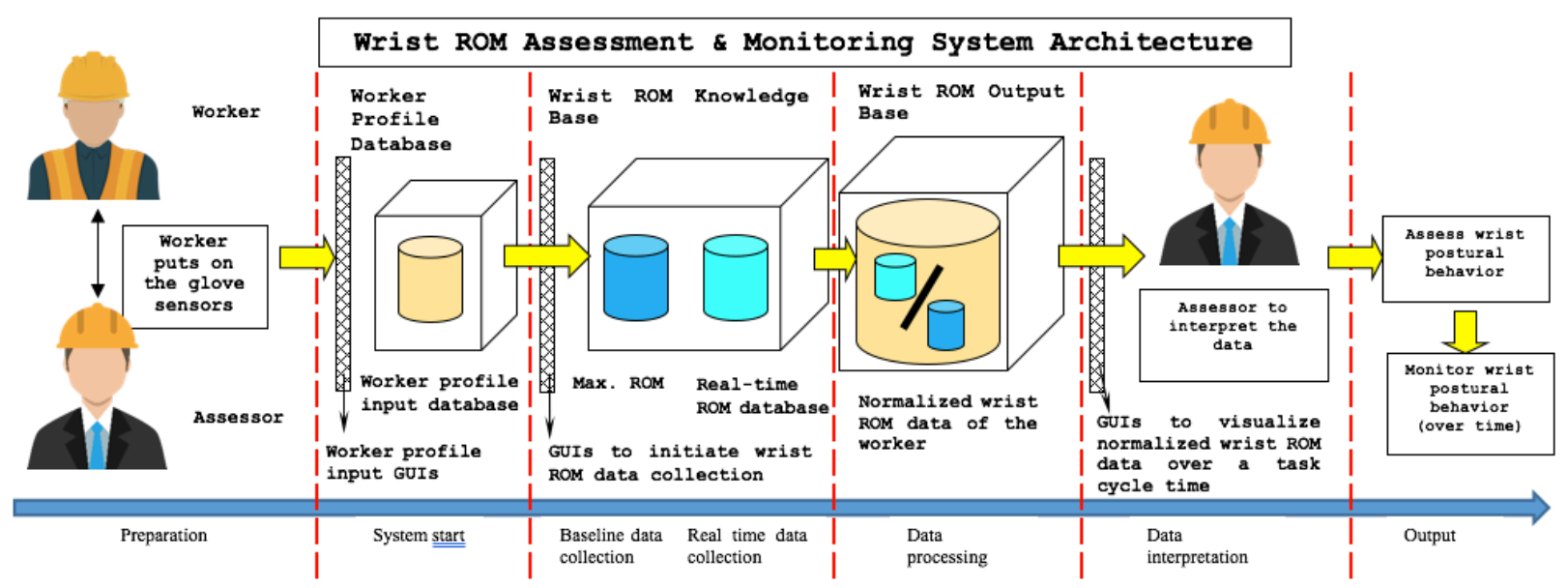

\begin{tabular}{|c|c|}
\hline Steps & Activities \\
\hline 2 & System start: Worker's demographic information will also be captured and a profile will be created. \\
\hline 3 & $\begin{array}{l}\text { Baseline data collection: Capturing worker's maximum range of wrist motion as baseline data: The worker will be asked to } \\
\text { perform maximum voluntary wrist extension, flexion, ulnar and radial deviation. }\end{array}$ \\
\hline 5 & Data processing and analysis: Normalize worker's real-time data against the baseline data. \\
\hline 6 & Data interpretation: Analyze the distribution of normalized wrist motion data over the task cycle. \\
\hline
\end{tabular}

Fig. 2 Conceptual architecture of wrist range-of-motion (ROM) assessment system to assess and monitor wrist postural behaviors at workplace.

The proposed system starts with the worker wearing the wearable glove attached to Inertial Measurement Unit (IMU) sensors (which consisted of accelerometer and gyroscope). The worker's demographic information will then be entered into the system to set-up a database profile. Once the profile is set-up, the worker will be asked to perform a series of maximum voluntary ROM on wrist extension, flexion, ulnar and radial deviations as shown in Figure 3. The two-axis maximum range of motion are saved in a Wrist ROM Knowledge Base, and intended to be the baseline maximum reference data. A maximum ROM envelope will be generated from this baseline data. All other ROM data captured afterward will be compared to this baseline reference.

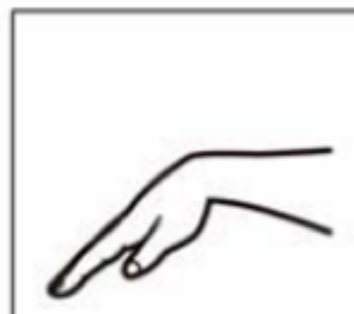

(a)

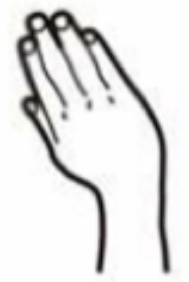

(c)

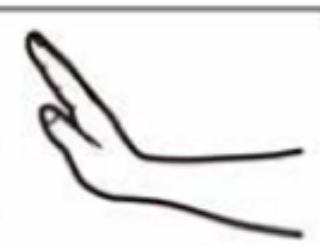

(b)

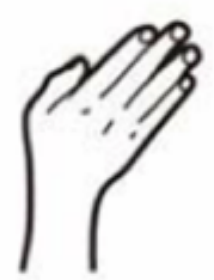

(d)
Fig. 3 Wrist positions captured in the proposed system (adapted from Keir et al.[7] ) : (a) wrist flexion; (b) wrist extension; (c) wrist radial deviation; (d) wrist ulnar deviation.
The next step involves having the worker perform / simulate occupational task while the system captures the realtime wrist motion behavior. The data will be captured and stored in the Wrist ROM Knowledge Base. This knowledge base consisted of programming rules to compute the percentage of real time wrist ROM data normalized to the maximum voluntary wrist ROM. A Graphical User Interface (GUI) will display the normalized wrist ROM data in real time. The raw and normalized data over the recorded cycle time will also be saved in the system, and can be extracted if further analysis is required. The output of the system will provide a summary of wrist postural behavior assessment from the real time normalized wrist ROM data distributed over a period of task cycle. Monitoring of wrist postural behavior can be conducted through a periodic application of the system.

\section{3 - Experts' opinion on the architecture}

Overall, the feedback from the experts on the system's architecture were positive. They were generally in agreement on the overall process flow of the system's architecture. The experts described the system's architecture to be novel in that it offers a new insight on an alternative way to assess specific postural behavior at work. They all recounted their experience that current assessment and monitoring tools specific on wrist posture are limited in number and capabilities. Among issues reported were that the rapid dynamic movements of the wrist are hard to capture in actual work settings, and the traditional methods of using observation and goniometer limits the quality of data sampling.

The experts agreed on the advantages of having a specific tool to assess and monitor wrist posture, especially in work settings where wrist movements are common. They also agreed on the theoretical advantage of having an overview of the postural data over a period of time (cycle time) instead of snap shot of a representative posture. In addition, the idea to integrate personal limitation (such as the existing WMSD onset) into the system was also intriguing to them. The experts reported the idea of normalizing the worker's wrist 
ROM against own maximum voluntary ROM to be an interesting idea that should be further explored.

Discussion on the system's postural data output also involves capturing other types of data that are previously challenging to capture, but provide opportunity for deeper analysis. For example, one practitioner pointed out that capturing continuous sample of postural data using IMUs, which consists on accelerometers may allow an overview of the acceleration and speed of wrist angle changes during the assessment period. Objective data on acceleration and speed of wrist motion may provide engineers numerical parameters to consider when exploring intervention solutions. The data also provides ergonomists, biomechanics engineers and health practitioners a more detailed information to calculate biomechanics loading and exposure to the wrist. In addition, the ROM normalization process allows practitioners to better analyze the magnitude and percentage distribution of poor wrist posture over the cycle time, which will then allow them to better describe their assessments to their clients / managements. All three experts reported they can envision to have the system be used in both industrial and academic settings.

There was no significant concern raised on the presented conceptual architecture of the system. However, some future concerns of the system projected by the experts involved the accuracy, reliability, usability, and practicality. The accuracy and reliability of the sensor to detect the postural angle was brought up, and the validation process to compare the postural angle between the sensor and goniometer was discussed as an essential stage to the system development. In terms of accuracy and reliability, a previous study using glove with sensors to capture angular displacements has demonstrated that the sensors can provide accurate measurements as those given by the traditional goniometer [38]. A concern was also projected on the usability of the system, in terms of GUI design to assist assessor with interpretation of postural data. Proper GUI design involving end users was then suggested to ensure usability of the system to be developed. Lastly, the experts also pointed out some practicality concerns of the system during assessment, such as the bulkiness of glove sensors that may interfere with certain tasks (e.g. high precision assembly task), or limited hand clearance (e. g. feeding machine task). They concluded that these concerns, as well as the scopes and limitations of the system need to be further explored and identified during the development process.

\section{Discussion}

This proposed method is novel in that it tries to incorporate few new components in the process of assessing and monitoring of wrist postural behavior at work. The components are envisioned to address several research gaps associated with current ergonomics wrist assessment at work. First, the proposed method may increase the specificity of assessment as it specifically focuses on wrist, compared to tools like RULA, REBA, and OCRA which only put a limited weight on wrist posture behavior. Secondly, by using an instrument (IMU sensors), objective data can be captured and analyzed rather than current methods that leans heavily on subjectivity of assessors' experiences. Thirdly, the instrumentation in this proposed method allows capturing of rapid changes in postural movements. Thus, the postural data captured will be a high resolution, dynamic real-time data instead of a 'snapshot' as it was in existing assessment tools such as RULA, REBA, etc. These objectivity and real-time types of data may potentially improve the validity component of the assessment. The fourth gap is that the current assessment systems are limited in terms of measuring individual differences in postural capacity. Thus, two workers on similar workstation, performing similar task, may adopt the same wrist posture with similar postural angle. However, the worker who already has an onset of wrist pain and discomfort might be exposed to higher risk of injuries compared to the colleague with healthy wrist. The traditional postural assessment methods that use the absolute angle as a measure instead of ROM may not capture this individual factor in their risk assessment process. As such, the workers with advance stages of MSDs development might not be rated differently with other healthy workers using the traditional methods.

It is well known that the development of MSDs is multidimensional. Several factors such as task, technology, environment, work organization, and personal factors interact with each other to form unique occupational contexts [39]. The situational context created from the interactional incompatibilities between these factors, filtered through the individual worker's unique circumstances may result in strains at biomechanical, physiological or even at psychological levels. Continuous misfits of these interacting factors will eventually lead to chronic development of biomechanical, physiological or psychological disorders, as shown in Figure 4.

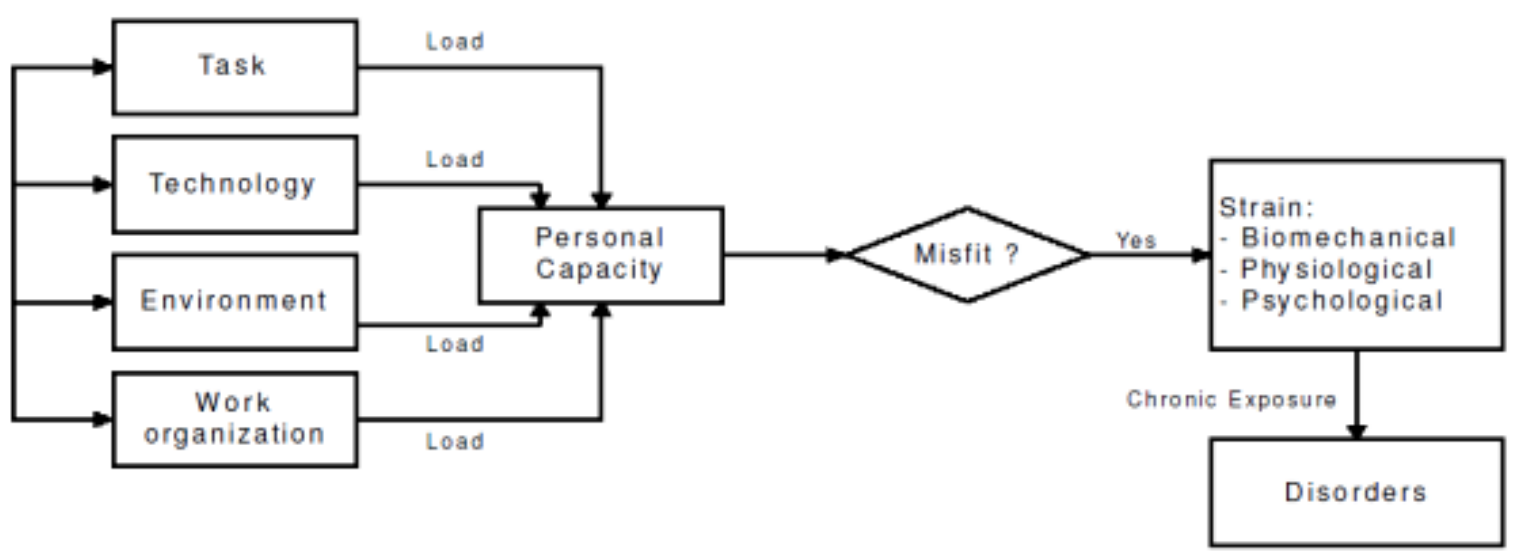

Fig. 4 Conceptual model of the development of work-related musculoskeletal disorders [40]. 


\section{Radin Zaid Radin Umar, Nadiah Ahmad, Isa Halim and Nazreen Abdullasim/}

Journal of Engineering Science and Technology Review 12 (6) (2019) 80 - 86

The strain occurs when the misfit happens at the personal level. However, it should be noted that the personal capacity factors may be different from one person to another. Few studies have shown that restricted ROM can affect individuals' functional ability [41, 42] and in extension, work ability. Thus, an assessment that considers both work factors (such as task, technology, etc.) as well as individual factors (such as current wrist health condition) is expected to provide a higher sensitivity of measure. The proposed system is partly inspired by the well-established use of EMG ergonomics assessment method such as from Sommerich et al. [43, 44] and Lavender et al.[45] , which evaluates the individual capacity through normalization of real time muscle activity data over the maximum voluntary exertion. Normalizing data to maximum capacity may provide a higher sensitivity to capture development of WMSDs risks due to individual factors.

Future works include fabrication of the system's hardware and software, as well as conducting validity and usability studies. The hardware involves the use of IMU sensors attached to wearable gloves. The positional data from IMU will be converted to angular displacement data through custom algorithm in a computer processing unit. The software, which includes the knowledge base, output base, as well as the GUI of the system will be developed using programming language. Validity study will be conducted to compare the differences of wrist angular displacement captured in this proposed system against the traditional ROM capture using traditional goniometer. In addition, field studies to compare the new system with other assessment tools will also be conducted with inputs from ergonomists and industrial practitioners. Similarly, the usability study will also be conducted with inputs from ergonomists and practitioners. The study will focus on ease of use and overall user experience when using the proposed new system.

Future work may also include the investigation of the cutoff point on acceptable percentage of the normalized wrist ROM data at work. A prospective future study utilizing collected data may provide researchers an information on the levels of exposure that may be associated with the onset of wrist MSDs. Alternatively, a study involving psychophysical components may also be conducted in order to project this normalized cutoff point. Further studies of this proposed system may also be focusing on developing an index for normalized wrist ROM to predict the likelihood of occupational injuries.

\section{Conclusion}

In summary, the new conceptual architecture proposed in this study is expected to contribute a new way of assessing and monitoring wrist behavior at work. The suggestion involves the idea of considering both the work factors (wrist posture behavior due to task, equipment, environment layout) and individual factor (maximum ROM capacity for the worker being assessed) in its assessment and monitoring system. It is envisioned that this proposed system may provide a more sensitive and specific method to assess and monitor wrist postural behaviors at work. It is expected that this research endeavor will bridge gaps between academic research and practice, and contribute in assisting industrial practitioners perform ergonomic evaluation. This endeavor is expected to provide pathway to reduce workers' exposure to safety risk factors, and ultimately improving the overall occupational safety and health of workers.

\section{Acknowledgements}

The authors are grateful to the Malaysian Government, Universiti Teknikal Malaysia Melaka (UTeM) for supporting this study. This study is funded by the UTeM Seed Money Grant (PJP/2016/FKP-AMC/S01501).

This is an Open Access article distributed under the terms of the Creative Commons Attribution License

\section{References}

1. F. Gerr, N. B. Fethke, L. Merlino, D. Anton, J. Rosecrance, M. P. Jones, M. Marcus, and A. R. Meyers. "A Prospective Study of Musculoskeletal Outcomes among Manufacturing Workers: I. Effects of Physical Risk Factors.” Human Factors. 56, 112 (2014).

2. US Department of Labor. "Nonfatal Occupational Injuries and Illnesses Requiring Days-Away-from-Work in 2014." Bureau of Labor Statistics (2015)

3. US Department of Labor. "The employment situation -Januanry 2017." Bureau of Labor Statistics (2017).

4. A. E. Barr, M. F. Barbe, and B. D. Clark. "Work-Related Musculoskeletal Disorders of the Hand and Wrist: Epidemiology, Pathophysiology, and Sensorimotor Changes." The Journal of Orthopaedic and Sports Physical Therapy. 34, 610 (2004).

5. V. Putz-Anderson, B. P. Bernard, S. E. Burt, L. L. Cole, C. FairfieldEstill, L. J. Fine, K. A. Grant, et al. "Musculoskeletal Disorders and Workplace Factors: A Critical Review of Epidemiologic Evidence for Work-Related Musculoskeletal Disorders of the Neck, Upper Extremity, and Low Back." DHHS (NIOSH), p. 97-141 (1997).

6. P. Y. Loh, and S. Muraki. "Effect of Wrist Deviation on Median Nerve Cross-Sectional Area at Proximal Carpal Tunnel Level." Iranian Journal of Public Health. 43, 180 (2014).

7. P. J. Keir, J. M. Bach, M. Hudes, and D. M. Rempel. "Guidelines for Wrist Posture Based on Carpal Tunnel Pressure Thresholds." Human Factors. 49, 88. (2007).

8. B. K. K. Fung, K. Y. Chan, L. Y. Lam, S. Y. Cheung, N. K. Choy, K. W. Chu, L. Y. Chung, et al. "Study of Wrist Posture, Loading and
Repetitive Motion as Risk Factors for Developing Carpal Tunnel Syndrome." Hand Surgery. 12, 13 (2007).

9. C. Jensen, V. Borg, L. Finsen, K. Hansen, B. Juul-Kristensen, and H.Christensen. "Job Demands, Muscle Activity and Musculoskeletal Symptoms in Relation to Work with the Computer Mouse." Scandinavian Journal of Work, Environment \& Health. 24, 418 (1998).

10. P. Y. Loh, H. Nakashima, and S. Muraki. "Effects of Grip Force on Median Nerve Deformation at Different Wrist Angles.” PeerJ. 4, e2510 (2016).

11. C. E. De Putter, R. W. Selles, S. Polinder, M. J. M. Panneman, S. E. R. Hovius, and E. F. van Beeck. "Economic impact of hand and wrist injuries: health-care costs and productivity costs in a populationbased study." Journal of Bone and Joint Surgery. 94, e56 (2012).

12. M. J. Page, N. Massy-Westropp, D. O'Connor, and V. Pitt. "Splinting for Carpal Tunnel Syndrome." The Cochrane Library, Wiley \& Sons (2012).

13. J. S. Moore, and A. Garg. 1995. "The Strain Index: A Proposed Method to Analyze Jobs for Risk of Distal Upper Extremity Disorders." American Industrial Hygiene Association Journal. 56, 443 (1995).

14. A. Kilbom, M. Mäkäräinen, L. Sperling, R. Kadefors, and L. Liedberg. "Tool Design, User Characteristics and Performance: A Case Study on Plate-Shears.” Applied Ergonomics. 24, 221 (1993).

15. G-Å. Hansson, I. Balogh, K. Ohlsson, L. Rylander, and S. Skerfving. "Goniometer Measurement and Computer Analysis of Wrist Angles and Movements Applied to Occupational Repetitive Work." Journal of Electromyography and Kinesiology. 6, 23 (1996). 
Radin Zaid Radin Umar, Nadiah Ahmad, Isa Halim and Nazreen Abdullasim/

Journal of Engineering Science and Technology Review 12 (6) (2019) 80 - 86

16. E. B-N. Sanders and P. J. Stappers. "Convivial Design Toolbox: Generative Research for the Front End of Design." Abingdon: BIS Publisher. (2012).

17. J. Saldaña. "The Coding Manual for Qualitative Researchers." Sage, London p. 1-31 (2012).

18. A. Garg, J. S. Moore, and Jay M. Kapellusch. "The Revised Strain Index: An Improved Upper Extremity Exposure Assessment Model.’ Ergonomics. 60, 912 (2017).

19. P. Drinkaus, R. Sesek, D. Bloswick, T. Bernard, B. Walton, B Joseph, G. Reeve, and J. H. Counts. “Comparison of Ergonomic Risk Assessment Outputs from Rapid Upper Limb Assessment and the Strain Index for Tasks in Automotive Assembly Plants." Work. 21 165 (2003a).

20. Y-W. Xu and A. S. K. Cheng. "An Onsite Ergonomics Assessment for Risk of Work-Related Musculoskeletal Disorders among Cooks in a Chinese Restaurant." Work. 48, 539 (2014).

21. A. Maldonado-Macias, M. G. Ramírez, J. L. García, J. J. Díaz, and S. Noriega. "Ergonomic evaluation of work stations related with the operation of advanced manufacturing technology equipment: Two cases of study." XV Congreso Internacional de ergonomia SEMAC (2009).

22. S. Goswami, S. Ghosh, and S. Sahu. "Evaluation of ergonomic risk factors in manual patient handling tasks of Indian nurses." Ergonomics. SA 29, 2 (2017).

23. M. Massaccesi, A. Pagnotta, A. Soccetti, M. Masali, C. Masiero, and F. Greco. 2003. "Investigation of work-related disorders in truck drivers using RULA method." Applied Ergonomics. 34, 303 (2003).

24. A. Gholami, A. Soltanzadeh, R. Abedini, and M. Sahranavard. "Ergonomic assessment of musculoskeletal disorders risk by Rapid Upper Limb Assessment (RULA) technique in a porcelain manufacturing factory." Journal of Research and Health. 4, 608 (2014).

25. E. H. Sukadarin, B. Md Deros, J. A. Ghani, A. R. Ismail, N. S. Mohd Nawi, and N. Abdull. "Validity Test for Simple Ergonomics Risk Assessment (SERA) Method." Malaysian Journal of Public Health Medicine 1. Special Issue 1, 134 (2016).

26. L. McAtamney and E. N. Corlett. "RULA: A Survey Method for the Investigation of Work-Related Upper Limb Disorders." Applied Ergonomics. 24, 91 (1993)

27. S. Hignett and L. McAtamney. "Rapid Entire Body Assessment (REBA)." Applied Ergonomics. 31, 201 (2000).

28. E. Occhipinti. "OCRA: A Concise Index for the Assessment of Exposure to Repetitive Movements of the Upper Limbs." Ergonomics. 41, 1290 (1998)

29. G. David, V. Woods, G. Li, and P. Buckle. "The Development of the Quick Exposure Check (QEC) for Assessing Exposure to Risk Factors for Work-Related Musculoskeletal Disorders." Applied Ergonomics. 39, 57 (2008).

30. P. Drinkaus, R. F. Sesek, D. S. Bloswick, C. Mann, and T. Bernard "The Hand Activity Level: Using Task Level Outputs to Evaluate Job Risk." 1 st Annual Regional National Occupational Research Agenda (NORA) Young/New Investigators Symposium, p. 11 (2003b).

31. D. S. Eini, N. Z. Ratzon, A. A. Rizzo, S-C. Yeh, B. Lange, B. Yaffe, A. Daich, P. L. Weiss, and R. Kizony. "Camera-Tracking Gaming
Control Device for Evaluation of Active Wrist Flexion and Extension." Journal of Hand Therapy. 30, 89 (2017).

32. W. S. Marras, F. A. Fathallah, R. J. Miller, S. W. Davis, and G. A Mirka. "Accuracy of a Three-Dimensional Lumbar Motion Monitor for Recording Dynamic Trunk Motion Characteristics." International Journal of Industrial Ergonomics. 9, 75 (1992).

33. L. Dipietro, A. M. Sabatini, and P. Dario. "Evaluation of an Instrumented Glove for Hand-Movement Acquisition." Journal of Rehabilitation Research and Development. 40, 179 (2003).

34. J. B. Rowe, N. Friedman, M. Bachman, and D. J. Reinkensmeyer. "The Manumeter: A Non-Obtrusive Wearable Device for Monitoring Spontaneous Use of the Wrist and Fingers." IEEE International Conference on Rehabilitation Robotics (2013).

35. M. Esmaeili, S. Guy, W. D. Dailey, E. Burdet, and D. Campolo. "Subject-Specific Wrist Model Calibration and Application to Ergonomic Design of Exoskeletons." IEEE Sensors Journal. 13, 3293 (2013).

36. M. L. Rawes, J. B. Richardson, and J. J. Dias. “A New Technique for the Assessment of Wrist Movement Using a Biaxial Flexible Electrogoniometer." Journal of Hand Surgery: European. 21, 600 (1996).

37. N. Vignais, M. Miezal, G. Bleser, K. Mura, D. Gorecky, and F. Marin. "Innovative system for real-time ergonomic feedback in industrial manufacturing." Applied Ergonomics. 44, 566 (2013).

38. N. W. Williams, J. M. T. Penrose, C. M. Caddy, E. Barnes, D. R. Hose, and P. Harley. "A Goniometric Glove for Clinical Hand Assessment." Journal of Hand Surgery. 25, 200 (2000).

39. R. Z. R. Umar. "Investigation of Factors Influencing the Adoption of Safety-Related Changes during the Early Stages of Implementation: An exploratory Study." PhD Diss., OSU (2015).

40. B. T. Karsh, Ben Tzion, F. B. P. Moro, and M. J. Smith. "The Efficacy of Workplace Ergonomic Interventions to Control Musculoskeletal Disorders: A Critical Analysis of the PeerReviewed Literature." Theoretical Issues in Ergonomics Science. 2 23 (2001).

41. O. I. Franko, D. Zurakowski, and C. S. Day. "Functional Disability of the Wrist: Direct Correlation With Decreased Wrist Motion." Journal of Hand Surgery. 33, 485 (2008).

42. P. Srivanitchapoom, E. A. Shamim, P. Diomi, T. Hattori, S. Pandey, S. Vorbach, J. E. Park, T. Wu, S. Auh, and M. Hallett. "Differences in Active Range of Motion Measurements in the Upper Extremity of Patients with Writer's Cramp Compared with Healthy Controls." Journal of Hand Therapy. 29, 489 (2016).

43. C. M. Sommerich, S. A. Lavender, R. Z. R. Umar, J. Li, S. H. Park, and M. Dutt. "A Biomechanical and Subjective Comparison of Two Powered Ambulance Cots.” Ergonomics. 58, 1885 (2015).

44. C. M. Sommerich, J. Li, S. Nagavarupu, D. Palmer, S. Ngo, R. Z. R. Umar, D. Keester, and J. Dickerson. "A Pilot Study of an Articulating Support Arm System for Reducing Sustained Posture and Muscular Effort While Performing Echocardiograms." Proceedings of the Human Factors and Ergonomics Society Annual Meeting. 60, 1492 (2016).

45. S. A. Lavender, K. M. Conrad, P. A. Reichelt, J. Gacki-Smith, and A. K. Kohok. "Designing Ergonomic Interventions for EMS Workers, Part I: Transporting Patients down the Stairs." Applied Ergonomics. 38, 71 (2007) 